\title{
Examining Of the Elementary Teacher Candidates' Knowledge Levels Regarding Fourth Grade Science Course Units in Elementary School
}

\author{
Gökhan UYANIK
}

\author{
Summary
}

\section{INTRODUCTION}

Teaching profession a position in educational organizations and creates a set of behaviors that stipulated that position, the position status is a concept that refers to the tasks and relationships. Teachers constantly update their knowledge and they must constantly updating themselves. For this, firstly it has a sufficient level of success in the field of knowledge and they should provide the necessary competence. Competence, knowledge must-have for a successful fulfillment of the professional aspects of a profession refers to skills and attitudes. The teaching profession, according to considered to be a profession that requires specialist knowledge and skills of the people who enter this profession to be able to fully meet the requirements of their profession, they must have some competence. Teachers must have an extensive world and culture in general, should know better to teach the subject field, and must have the knowledge and skills related to the teaching-learning process. What a teacher knows the area well, also he knows how to teach well enough. Therefore, a strong knowledge of the area, having been one of the features expected of teachers. Each elementary teacher is obliged to teach courses related science in third and fourth grade primary school. In this regard the elementary teachers at primary school science related units to know exactly where the issues should possess sufficient knowledge of the field in this area. Elementary teacher candidates of science topics related to missing or incorrect knowledge of themselves can cause them to feel inadequate for teaching. In this sense, the teaching-learning process in the elementary teachers' basic knowledge of the subject area related to science, said that it is extremely important. Hence, the purpose of this research is to examine the elementary teacher candidates' knowledge levels regarding the elementary school fourth grade science course units. For this aim is to answer the following sub-problems;

1. How is the knowledge levels of elementary teacher candidates at different grade levels related to primary school fourth grade science course units?

2. Is there a significant difference between according to the grade level, the knowledge levels related to science course units of elementary teacher candidates?

\section{METHOD}

This research is designed to survey model. Sample of the study consists of 411 teacher candidates who were studying in elementary teaching degree first $(\mathrm{N}=82)$, second $(\mathrm{N}=117)$, third $(\mathrm{N}=114)$ and fourth grade $(\mathrm{N}=98)$ levels. As data collection tool the achievement tests were used relating science units of elementary $4^{\text {th }}$ grade developed by Uyanik (2014). The first units' achievement test (U1) was consisting of 23 questions. The tests' KR-20 reliability coefficient was calculated as 0.82 . The second units' achievement test (U2) was consisting of 28 questions. The tests' KR-20 reliability coefficient was calculated as 0.78 . The third units' achievement test (U3) was consisting of 20 questions. The tests' KR-20 reliability coefficient was calculated as 0.83 . Data were analyzed using SPSS 21.0 statistical software package. One- 
way ANOVA test was used to analyze the data. Addition to this, Tamhane's T2 test was used in order to make a multiple comparison. Results was tested the $p<.05$ level of significant.

\section{FINDINGS}

According to the findings, elementary teaching degree program students who were studying in different grade levels, indicating that there was a statistically significant difference

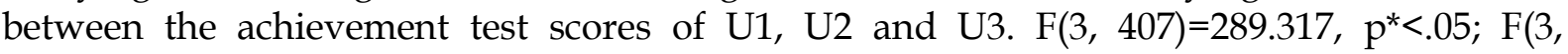
$407)=35.985, \mathrm{p}^{*}<.05 ; \mathrm{F}(3,407)=126.073, \mathrm{p}^{*}<.05$. It was determined that there was a significant difference between the achievement test scores of first, second graders and third graders in favor of third grade students. Furthermore, it was determined that there was a significant difference between the achievement test scores of first, second graders and fourth graders in favor of fourth grade students. According to average scores of achievement test, the difference between the achievement test scores of the first and second grade teacher candidates were determined not to be statistically significant. Besides the difference between the achievement test scores of the third and fourth grade teacher candidates were determined not to be statistically significant. Considering the average scores, the third and fourth graders' scores of achievement tests were higher than the first and second graders.

\section{DISCUSSION AND RECOMMENDATIONS}

At the end of the research while average achievement test scores were very close to that of the first and second grade students. Furthermore, the third graders and fourth graders' average scores of achievement tests were found to be very close and their average scores were higher than the first and second graders. The results of this research, even serious mistakes regarding the meaning of science units of elementary fourth grade, they have researched not enough about the concept of teacher candidates was perceived. These results supported some results of researches in related literature. It was determined that third and fourth grade students more successful than first and second graders about science course units' level of knowledge. This result was observed during the third year in fall semester classroom teaching degree programs science and technology instruction course, considered to be related science subjects learned in the lessons.

While teaching science subjects it is emerging that importance of will provide selecting effective and permanent methods. In this context of learning through the invention, research and investigation based science teaching, prediction-observation-explanation strategy, laboratory activities, transformational learning, doing-experiencing learning, cooperative learning and so on, student-centered teaching methods and techniques can use to be provision of effective and permanent science education. The importance of elementary education is very big in students' academic life. The basis of the science subjects they encounter during the academic life of students are largely disposed of in elementary school. Therefore, great importance should be given to the classroom teacher education. Providing accurate and indept understanding teaching methods emerging as a necessity to better cultivating classroom teachers in education faculties of universities. 